\title{
A REORGANIZAÇÃO URBANA DAS METRÓPOLES PERIFÉRICAS NA ERA DA FINANCEIRIZAÇÃO GLOBAL DO CAPITAL
}

\section{THE REORGANIZATION OF URBAN PERIPHERAL METROPOLISES IN THE ERA OF GLOBAL CAPITAL FINANCIALIZATION}

\author{
Lisiane Paixão Silva Oliveira ${ }^{1}$ \\ Diogo de Calasans Melo Andrade ${ }^{2}$ \\ Rita de Cassia Barros de Manezes ${ }^{3}$
}

\begin{abstract}
Resumo
A globalização faz com que lugares se internacionalizem-se, transformando todas as cidades do mundo em um só lugar. A qualidade da vida urbana tornou-se uma mercadoria. Já a financeirização defende menos Estado e transforma o espaço urbano em ativo financeiro, capturando o público pelo privado. No mundo, governos renunciam seu papel de provedores da habitação para tornarem-se, apenas, facilitadores, criando um setor financeiro habitacional. Essas políticas de financeirização faz crescer o mercado financeiro, tornando possível ganhar mais dinheiro com as transações financeiras do que construindo novas moradias. A financeirização da moradia existe nos países capitalistas e, apesar da divergência doutrinária, defende-se, nesse artigo, que a financeirização existe nos países periféricos. Aqui esse processo está ligado às reformulações urbanas fundadas na remoção, com, por exemplo, a desapropriação dos imóveis da favela. Para o presente trabalho realizamos uma revisão da literatura de autores estrangeiros, como David Harvey e Henri Lefebvre, além dos principais autores brasileiros que escrevem sobre a matéria. Percebeu-se, também, que a política urbana no Brasil está sendo entregue nas mãos dos interesses imobiliários e financeiros privados, sendo o maior exemplo disso o Programa Minha Casa Minha Vida (PMCMV).
\end{abstract}

Palavras-chaves: política urbana, moradia, financeirização, mercadoria.

\section{Summary}

Globalization makes places to internationalize, transforming every city in the world in one place. The quality of urban life has become a commodity. In other hand financialization advocates less state and transforms the urban space in a financial asset, capturing the public from the private. Around the world, governments renounce its role of housing providers to become just facilitators, creating a housing finance sector. These financialization policies makes the financial market grow, making it possible to make more money from financial transactions than building new housing. The housing financialization exists in the capitalist countries, and despite the doctrinal divergence, it is argued in this article in favor of financialization in the peripheral countries, including Brazil. Here this process is linked to urban reformulations based on the removal, with the dispossession of the slum properties. For this paper we conducted a literature review of foreign authors such as David Harvey and Henri Lefebvre, in addition to the main Brazilian authors who wrote on the subject. It

\footnotetext{
${ }^{1}$ Doutora em Direito pela Université d’Aix-Marseille III. Coordenadora e Professora do Programa de PósGraduação em Direito - Mestrado em Direitos Humanos da Universidade Tiradentes. E-mail: liziane_paixao@unit.br

${ }^{2}$ Doutorando em direito pela Mackenzie. E-mail: contato@diogocalasans.com

${ }^{3}$ Doutoranda em direito pela Mackenzie. E-mail: ritacassiamenezes@uol.com.br
} 
was noticed also that urban policy in Brazil is being delivered into the hands of real estate and private financial interests, the largest example is the "Minha Casa Minha Vida" (PMCMV)

Keywords: urban policy, housing, financialization, merchandise. 


\section{INTRODUÇÃO}

A globalização pode ser analisada sob diversas perspectivas, uma vez que traz consequências tanto positivas como negativas ao meio ambiente, às cidades e aos indivíduos que nelas residem, verificando-se principalmente grande impacto no processo de moradia, por causar a migração dos indivíduos da zona rural para a zona urbana.

A discussão acerca da globalização e seus impactos é um tema sempre relevante e atual, em virtude da polêmica em torno de sua conceituação, já que tal processo pode ser analisado sob diversos pontos de vista, a partir da cultura, economia, educação, como também, a análise dos diversos reflexos que causam significativas alterações na cidade, e que acabam envolvendo também, outra discussão não menos importante, acerca da governança, ou seja, a forma de como o Estado exerce o poder e administra os recursos sociais e econômicos do país com o intuito de alcançar o desenvolvimento, necessitando para tal, de planejamento e implementação de políticas públicas, no caso em análise, de programas sociais voltados à moradia.

O presente artigo aborda a importância da boa governança e eficaz articulação do governo com a sociedade para que se possa alcançar um concreto desenvolvimento das cidades, através da implementação de políticas públicas no tocante à moradia, constituindo-se esta articulação uma eficaz estratégia para o alcance de benefícios da população que reside nos centros urbanos.

Através do presente trabalho pode-se constatar que o processo de globalização modifica a vida e o bem-estar do indivíduo, sobretudo na zona urbana, refletindo diretamente na sua qualidade de vida do cidadão, que passa a ser considerada mercadoria, onde o mesmo torna-se refém do consumismo, de novas atividades culturais e econômicas, influenciando também diretamente em aspectos políticos e econômicos das cidades, sendo que o processo de urbanização das últimas décadas é responsável também pelo aumento de violência, pobreza e depredação do meio ambiente nos centros urbanos.

Outro importante aspecto abordado no trabalho em tela, é acerca da financeirização da moradia nas cidades, fruto da moradia-mercadoria e do deslocamento do homem da zona rural para a zona urbana, tendo como um dos principais efeitos a transformação do espaço urbano em um agente ativo financeiro.

Assim, procura-se demonstrar que o processo de financeirização da moradia no mundo e, especialmente, no Brasil, instaura-se por um processo de políticas que beneficiam muito mais o mercado de financiamento privado, do que o fomento de políticas públicas de moradia para os 
indivíduos de baixa renda, por isso o país investe mais em transações de casas construídas por empresas particulares, leia-se construtoras, do que em construção de novas casas através de políticas públicas. Neste contexto, o presente trabalho procura demonstrar que o país investe mais no financiamento particular de casas, independente de beneficiarem pessoas de baixa renda ou não, do que em políticas públicas de moradia destinadas à classe pobre da sociedade

Para tanto, se realizou um procedimento de revisão da literatura, estrangeira e brasileira, com a sistematização e análises de dados, buscando identificar os institutos, tendo como principais fontes de pesquisa os sites do governo federal, livros, periódicos.

\section{A GLOBALIZAÇÃO E SUA INTERFERÊNCIA NO DIREITO SOCIAL À MORADIA}

Através de uma análise crítica dos impactos da globalização no processo de moradia e as consequências visivelmente perceptíveis nas cidades, mister se faz, inicialmente, a discussão de alguns conceitos importantes à compreensão do tema. Torna-se imperiosa a discussão acerca da globalização, através de uma discussão teórica, que inclusive envolve a dificuldade de sua conceituação. Boaventura Santos "mostra que é imperioso produzir uma reflexão teórica crítica da globalização e de o fazer de modo a captar a complexidade dos fenômenos (sic) que ela envolve e a disparidade dos interesses que neles se confrontam" (2005, p. 54).

Assim, discutindo-se o conceito de globalização, pode-se dizer que possui várias dimensões, e pode ser analisada sobre diversos aspectos, entre eles, econômico, financeiro, tecnológico, ecológico, cultural, sendo que a área mais impactada pelo processo de globalização com importantes alterações foi a econômico/financeira, objeto de análise deste artigo, por refletir diretamente no processo de moradia. Para Tiago Oliveira:

O fenômeno resultante desta reconfiguração do estabelecimento das relações entre agentes por todo globo terrestre possuiu dimensões econômicas, políticas, sociais, geográficas, demográficas, culturais, jurídicas, religiosas, linguísticas etc., complexamente ligadas. (2009, p. 51)

Pode-se dizer que a globalização, em seus aspectos positivos ou negativos, não há uma unanimidade acerca de sua conceituação, sendo inclusive, este objeto de estudo de diversas correntes políticas. No entendimento de Spina Forjaz, o sociólogo Anthony Giddens considera que as divergências relativas ao conceito de globalização referem-se fundamentalmente ao conflito ideológico/político entre neoliberais e social-democratas ou socialistas ou, em última instância, ao conflito entre direita e esquerda como ele se manifesta atualmente. (Forjaz, 2000, p. 38-50) 
Assim, tendo em vista a globalização não ser definida através de um único e imutável conceito, proporcionando diversas discussões acerca de seus aspectos, pode-se dizer que a mesma deve ser conceituada levando-se em conta algumas exigências, no entendimento de Goran Therborn:

Como conceito de teoria e análise social, globalização deve dar conta de três tipos de exigências: deve ter um significado preciso, de preferência não arbitrário do ponto de vista semântico; deve ser passível de uso em investigações empíricas e ter uma ampla possibilidade de aplicação; a terceira exigência é que o conceito deve ser abstrato, não contendo qualquer conteúdo concreto a priori. Com base nessas considerações, parece-me importante definir a globalização estando relacionada a tendências de alcance, impacto ou encadeamento globais dos fenômenos sociais, ou a uma consciência de abrangência mundial entre os atores sociais. (2001, p. 125)

Desta forma, pode-se observar que o conceito de globalização se transforma, sob vários aspectos culturais, sociais, econômicos e políticos, constituindo-se em um modo de enfocar a realidade, podendo ser utilizada como auxílio nas mais diversas formas de visão do mundo.

Vale dizer que o processo de globalização influencia em diversas áreas da sociedade devendo ser, portanto, analisado sob vários critérios de legitimação social e de um novo diálogo intercultural, tendo em vista os processos de exclusão e de dominação trazidos pelo capital financeiro que refletem diretamente nas cidades. Conforme o pensamento de Carlos Wolkmer,

Diante dos recentes processos de dominação e exclusão produzidas pela globalização, pelo capital financeiro e pelo neoliberalismo que vêm afetando substancialmente relações sociais, formas de representação e de legitimação, impõe-se repensar politicamente o poder de ação da comunidade, o retorno dos agentes históricos, o aparecimento inédito de direitos relacionados às minorias e à produção alternativa de jurisdição, com base no viés interpretativo da pluralidade de fontes (2006, p. 114).

A complexidade das alterações que surgem na cidade devido ao processo de globalização envolvem outra importante discussão acerca da governança, ou seja, a forma de se exercer o poder e administrar os recursos sociais e econômicos do país para alcançar o desenvolvimento, através de planejamento e implementação de políticas públicas, estando relacionado diretamente com os atos do Estado. A respeito de governança Corralo afirma que:

Na esteira fomentada pelo Banco Mundial, especialmente com o documento Governance and Development 14, de 1992, elaborou-se um conceito próprio para a palavra governança, a abarcar centralmente as ideias de participação e desenvolvimento na gestão do poder: "[...] governance is defined as the manner in which power is exercised in the management of a country's economic and social resources for development" ou seja, "[...] governança é definida como a maneira na qual o poder é exercido na gestão dos recursos 
econômicos e sociais para o desenvolvimento". (Grifo do autor, Corralo, 2015, p. 86)

Desta forma, pode-se perceber a importância da boa governança para se alcançar uma concreta articulação do governo, da sociedade e dos gestores econômicos em prol do desenvolvimento das cidades, neste aspecto, tornando-se importante uma orientação de políticas públicas no tocante à moradia como estratégia para o desenvolvimento.

A globalização acompanha as ideias neoliberais que defendem a desregulamentação e privatização dos serviços públicos, acabando com o subsídio, eliminando a possibilidade de planejar e implantar políticas públicas voltadas aos países da periferia do capitalismo, como o Brasil. Especificamente no nosso país essas ideias trazidas pela globalização vão ao encontro do nosso sistema político, muitas vezes fundamentados no patrimonialismo e em uma sociedade que não universalizou seus direitos sociais, em destaque a moradia.

Assim, faz-se necessário a análise desses problemas, como também a participação social nos destinos de uma comunidade e, por fim, a reforma fundiária, como ensina Maricato:

Finalmente, nunca é demais repetir o que é muito óbvio, mas pouco considerado na sociedade global, que a ausência de controle público sobre a propriedade da terra contribui para a carência habitacional, segregação territorial, aumento do custo da infraestrutura e serviços, além de impor maior sacrifício à população pobre excluída da cidade. A "desordem" do mercado fundiário e imobiliário (que evidentemente pressupõe uma outra "ordem") impõem custos à administração pública que resultam em rendas diferenciais apropriadas privadamente. (2009, p. 22)

A ausência de controle público sobre a propriedade privada contribui para a falta de moradia, segregação territorial, aumento dos custos, sacrificando a população pobre. Essa desordem do mercado imobiliário impõe ao Estado custos e renda para o setor privado imobiliário.

Por outro lado, a globalização trouxe também aumento do desemprego, precarização das relações de trabalho, diminuição de políticas públicas, privatização, mercantilização dos serviços públicos, a desigualdade social e, principalmente, a exclusão social, com bairros, cidades ou regiões esquecidas pelo Estado. Assim, adverte Santos sobre uma globalização como perversidade:

De fato, para a maior parte da humanidade a globalização está se impondo como uma fábrica de perversidades. O desemprego crescente torna-se crônico. A pobreza aumenta e as classes médias perdem em qualidade de vida. O salário tende a baixar. A fome e o desabrigo se generalizam em todos os continentes. Novas enfermidades como a SIDA se instalam e velhas doenças supostamente extirpadas, fazem seu retorno triunfal. A mortalidade infantil permanece, a despeito dos progressos médicos e da informação. A educação de qualidade é cada vez mais inacessível. Alastram-se e profundam-se males espirituais e morais, como os egoísmos, os cinismos, a corrupção. (2003, p. 10) 
Antes, eram as cidades dos notáveis, hoje se transforma em cidades econômicas. A cidade dos notáveis, onde as personalidades marcantes eram o padre, o tabelião, a professora primária, o juiz, o promotor, o telegrafista, cede lugar à cidade econômica, onde são imprescindíveis o agrônomo, o veterinário, o piloto agrícola, o especialista em adubos, o responsável pelos comércios especializados. A cidade se torna o locus da regulação do que se faz no campo. O campo de torna extremante diferenciado pela multiplicidade de objetos geográficos que o formam, pelo fato de esses objetos terem um conteúdo informacional cada vez mais distinto. Tudo isso faz com que a cidade local deixe de ser a cidade no campo e se transforme na cidade do campo. (SANTOS, 1990, p. 75)

Sobre a expulsão de bilhões de camponeses do campo por meio da globalização, explica Maricato:

A partir dos anos 1980, a globalização agravou o problema da terra. O incremento do agronegócio baseado no latifúndio elevou a importância estratégica de produtos primários como minérios, celulose, grãos, carne, petróleo e etanol, que ganharam importância estratégica nos mercados globais. Hoje, eles promovem a expulsão de camponeses do meio rural numa escala que virá ser contabilizada na casa dos bilhões de pessoas. (2014, p. 183)

A globalização faz com que os lugares e os indivíduos internacionalizem-se, unindo o mundo e transformando a terra em um só lugar, a instantaneidade da informação no mundo globalizado aproxima lugares e cria entre lugares uma relação única. Ela se exprime por meio de suas funcionalizações e uma delas é o espaço geográfico e, sobre a noção de espaço geográfico explica Santos:

É necessário talvez, e antes de tudo, explicitar a noção de espaço, de meio. Consideramo-lo como algo dinâmico e unitário, onde se reúnem materialidade e ação humana. O espaço seria o conjunto indissociável de sistemas de objetos naturais ou fabricados e de sistemas de ações, deliberadas ou não. A cada época, novos objetos e novas ações vêm juntarse às outras, modificando o todo, tanto formal quanto substancialmente. (1990, p. 23)

A cidade se transforma não apenas em razão de processos globais relativamente contínuos como crescimento da produção material no decorrer das épocas, com suas consequências nas trocas ou o desenvolvimento da racionalidade, como também em função de modificações profundas no modo de produção, nas relações cidade-campo, nas relações de classe e de propriedade. (LEFEBVRE, 2001, p. 58) 
De mais a mais, essa mesma globalização com as características robotização, terceirização, jus in time, mobilidade de capital, legislação ambiental menos rigorosa, leva à mudança na ocupação do território, adverte Maricato:

A robotização, a terceirização, a incorporação do just in time obedecendo a uma nova estratégica logística, a mobilidade do capital que transfere unidades de produção para regiões ou países onde a mão de obra é mais barata e a legislação ambiental, menos rigorosa, condenando ao abandono cidades marcadas pela produção fordista (como o clássico caso de Detroit), todas essas características da chamada globalização, levam a uma mudança na ocupação do território. (Grifo da autora - 2014. p. 173).

O processo de globalização acarreta a mundialização do espaço geográfico, cujas principais características são, além de uma tendência de um meio técnico, científico e informacional:

a. A transformação dos territórios nacionais em espaços de economia internacional;

b. A exacerbação das especializações produtivas no nível do espaço;

c. A concentração da produção em unidades menores, com aumento da relação entre produto e superfície - por exemplo a agricultura;

d. A aceleração de todas as formas de circulação e seu papel crescente na regulação das atividades localizadas, com o fortalecimento da divisão territorial e da divisão social do trabalho e a dependência deste em relação às formas espaciais e às normas sociais (jurídicas e outras) em todos os escalões;

e. A produtividade espacial como dado na escolha das localizações, o recorte horizontal e vertical dos territórios;

f. O papel da organização e dos processos de regulação na constituição das regiões;

g. A tensão crescente entre localidade e globalidade à proporção que avança o processo de globalização. (SANTOS, 1990, p. 24)

No Brasil, como os demais países da América Latina, apresentou intenso processo de urbanização, especialmente na segunda metade do século XX. Em 1940 a população urbana era de 26,3\% do total. Em 2000 ela era de 81,2\%. Esse crescimento se mostra mais impressionante ainda se lembrarmos os números absolutos: em 1940 a população que residia nas cidades era de 18,8 milhões de habitantes, e em 2000 era de aproximadamente 138 milhões.

Constatamos, portanto, que em 60 anos os assentamentos urbanos foram ampliados de forma a abrigar mais de 125 milhões de pessoas. Considerando apenas a última década do século $\mathrm{XX}$, as cidades brasileiras aumentaram em 22.718 .968 pessoas. Isso significa mais da metade da população do Canadá ou um terço da população da França. (MARICATO, 2000, p. 1-2)

O urbanista se inspira na prática de conhecimentos parciais que aplica ou então ele põe em ação hipótese ou projetos ao nível de uma realidade global. No primeiro caso, a aplicação dos conhecimentos parciais dá resultados que permitem a importância relativa desses conhecimentos. 
No segundo, o fracasso ou sucesso permite discernir o que existe de ideológico nas pressuposições e descobrir aquilo que elas definem ao nível global. (LEFEBVRE, 2001, p. 45)

Assim, a qualidade de vida urbana tornou-se uma mercadoria para os que têm dinheiro, como aconteceu com a própria cidade em um mundo no qual o consumismo, o turismo, as atividades culturais e baseadas no conhecimento, assim como o eterno recurso à economia do espetáculo, tornaram-se aspectos fundamentais da economia política urbana. A urbanização desempenhou um papel crucial na absorção de excedentes de capital, e que o tem feito em escala geográfica cada vez maior, mas o preço de processos de destruição criativa que implicam a desapropriação das massas urbanas de todo e qualquer direito à cidade (HARVEY, 2014, p.46 e 59).

Sabe-se que o movimento urbano tem necessidades a serem satisfeitas, quais sejam, trabalho, abastecimento, saúde, energia e água. O processo de urbanização no Brasil trouxe indicadores de violência, pobreza, predação urbana e ambiental, poluição do ar e da água etc. Após a industrialização no Brasil, os baixos salários de seus trabalhadores, obrigou parte deles a morarem nas favelas, uma vez que seu pequeno salário não incluía gasto com moradia.

Ocorre que essa industrialização, especificamente no Brasil, foi tardia em relação aos outros países e a consequência disso foi a manutenção do grande latifúndio improdutivo, que é uma característica essencial de um país patrimonialista como o Brasil, dificultando a ocupação às terras rurais.

Uma proporção maior ou menor da população urbana, dependendo de cada país, é excluída do direito à cidade e busca acesso à moradia por meio de seus próprios e precários recursos. Mesmo sem contar com levantamentos rigorosos (desconhecemos um país do mundo periférico que tenha contabilidade rigorosa sobre a moradia dos excluídos), podemos dizer que a maior parte da população urbana constrói suas casas sem o concurso de conhecimento técnico (de engenharia e arquitetura), sem financiamento formal e sem respeito à legislação fundiária, urbanística e edilícia. No Brasil, assim como em muitos países da América Latina, estima-se que $30 \%$ apenas da população tenham acesso à moradia no mercado privado. Nem mesmo aquilo que poderia ser classificado como classe média (5 a 10 salários mínimos) tem acesso à moradia por meio do mercado privado. (MARICATO, 2009, p. 09-10)

De mais a mais, a fiscalização por parte do Município, denominada de controle urbanístico, sobre o uso e a ocupação do solo ocorre somente na cidade legal, nas cidades ilegais (favelas), quando não interessam ao mercado imobiliário, essa fiscalização é ineficaz. Além do mais, a maior parte dos recursos públicos é destinada às cidades legais. 
É preciso considerar ainda que as periferias das metrópoles cresceram mais do que os núcleos centrais, o que implica um aumento relativo das regiões pobres. Das 12 regiões metropolitanas, os municípios centrais cresceram em média 3,1\% entre 1991 e 1996, enquanto os municípios periféricos cresceram 14,7\%. Dessas metrópoles, as periferias que mais se expandiram, no período, foram: Belém (157,9\%), Curitiba (28,2\%), Belo Horizonte (20,9\%), Salvador $(18,1 \%)$ e São Paulo (16,3\%) (Ipea, 1999). (MARICATO, 2000, p. 4)

Em algumas metrópoles, a diminuição do crescimento dos centros transformou-se em crescimento negativo dos bairros centrais. Há estudos que evidenciam essa dinâmica em São Paulo e no Rio de Janeiro (Silva, 1998). Em Belém, é o município central como um todo que apresenta crescimento negativo em contraposição ao gigantesco aumento dos municípios periféricos. (MARICATO, 2000, p. 4)

Por tudo isso, percebe-se que a globalização cria uma cidade virtual, longe do real e de seus problemas, fazendo com que os lugares se internacionalizem, transformando o mundo em um só lugar, ou seja, o processo de globalização leva à mundialização do espaço geográfico. A urbanização tem um importante papel na absorção de excedentes de capital. Já a qualidade de vida urbana torna-se mercadoria, exclusiva para aqueles que têm condições financeiras de comprála.

\section{A FINANCEIRIZAÇÃO E A MERCANTILIZAÇÃO DA MORADIA}

Sabe-se que as políticas públicas de moradia, ao invés de distribuir a riqueza e conceder uma habitação para aqueles que não têm, servem de mecanismo de extração de renda, lucro financeiro e acumulação de capital senão vejamos:

Há duas coisas que são confundidas gratuitamente e alegremente, isto é, a cidade e o urbano. O urbano é frequentemente o abstrato, o geral, o externo. A cidade é o particular, o concreto, o interno. Por isso, na realidade, há histórias do urbano e história da cidade. Entre as possíveis histórias do urbano estaria a história das atividades que na cidade se realizam, do emprego, das classes, da divisão do trabalho e de seu inverso, a cooperação. Entre as histórias da cidade, haveria a história dos transportes, a história da propriedade, da especulação, da habitação, do urbanismo, da centralidade. O conjunto das duas histórias nos daria a teoria da urbanização ou teoria da cidade (SANTOS, 1990, p. 34)

A financeirização está associada ao neoliberalismo, que prega menos Estado, mais contratos e governança ligados ao mercado. Seu intuito é transformar o espaço urbano em um 
ativo financeiro mais rentável em detrimento do direito à cidade. Para isso, o direito pode criar e modificar o espaço urbano através das leis, trazendo limites ao uso e a possibilidade de exploração do espaço urbano.

Sobre a financeirização da moradia explica Raquel Rolnik que se trata da conversão da economia política de habitação em elemento estruturador de um processo de transformação da própria natureza e forma de ação do capitalismo na era de hegemonia das finanças, do capital fictício e do domínio crescente da extração de renda sobre o capital produtivo, isto é, o domínio crescente de atores, mercados, práticas, narrativas (e subjetividades) financeiros em várias escalas, o que resulta na transformação estrutural de economias, empresas (inclusive instituição financeira), Estados e grupos familiares. (2015, p. 26-27)

Os efeitos da política urbana que tem como base a financeirização são a captura do público pelo privado, com progressiva flexibilização dos pactos participativos esculpidos, por exemplo, no Plano Diretor; a assunção pelo Estado dos riscos e despesas de vultosos empreendimentos, sem a respectiva distribuição de seus ganhos; e o aprofundamento da cisão social por intervenções pontuais que concentram ilhas globais num mar de exclusão são alguns dos efeitos perversos de uma política urbana que responde mais aos vetores da financeirização do que aos da democratização urbana. (HOSHINO, 2016, p. 2)

O movimento de tomada das terras por um capital financeirizado tem assumido várias formas, uma delas é a compra, após da regularização da propriedade e do registro como propriedade privada, como também, através das concessões remuneradas de terras por parte do Estado para que empresas privadas as explorem ou cultivem. (ROLNIK, 2015, p.161-167)

$\mathrm{Na}$ fase financeirizada e rentista do capital, as terras apropriadas sob regime de posse que não a propriedade individual titularizada e registrada, no campo e nas cidades, passam a funcionar como um reserva, passível de ser ocupada a qualquer momento por frações do capital em sua fome incessante de novas garantias para seus ativos, assim, de locus de um exército industrial de reserva, as favelas do mundo convergem-se em novas reservas de terra para extração de renda, sob a hegemonia do complexo imobiliário-financeiro. (ROLNIK, 2015, p.161-167)

A financeirização da economia é um processo longo que caminha com mais força com as desregulamentações promovidas nas economias nacionais desde a década de 1970 e que ganham impulso com as medidas do Congresso de Washington na década de 1980 e que mostrariam mudanças no sentido de preparar um novo regime dominante de acumulação do capitalismo: o financeiro. (VOLOCHKO, 2015, p. 114-115) 
A financeirização do setor imobiliário é realizada de modo lento e ainda um tanto dificultoso, dependendo de inúmeras variáveis macroeconômicas, institucionais, jurídicas, políticas e sociais que podem escapar ao seu controle, daí a constante tentativa de enquadramentos legais que respaldem as estratégias econômicas. (VOLOCHKO, 2015, p. 114-115)

Em 1993, o Banco Mundial anunciou um novo consenso no campo da política habitacional, sugerindo que os governos renunciassem a seu papel de provedores de habitação de custo acessível para se tornarem facilitadores, reorientando a sua política na direção de empréstimos das instituições financeiras, criando um setor financeiro habitacional nos países que sirva aos consumidores, financistas e governos, que seja capaz de dinamizar a economia. (ROLNIK, p. 79-84)

Esse abandono progressivo do financiamento de projetos urbanos faz crescer os empréstimos integrados, empréstimos para investimentos e subsídios no setor habitacional, além de assistência técnica, surgindo assim a financeirização da moradia e servindo essas políticas de financeirização muito mais para ampliar os próprios mercados financeiros do que aumentar o acesso à moradia. (ROLNIK, p. 79-84)

A cidade capitalista criou o centro de consumo. A produção industrial não constitui uma centralidade própria, salvo nos casos privilegiados da empresa importante em torno da qual se edificou uma cidade operária. Já é bem conhecido o duplo caráter da centralidade capitalista: lugar de consumo e consumo de lugar. O comércio se densificam no centro, que atrai os comércios raros, os produtos e gêneros de luxo. Esta centralidade se instala com predileção nos antigos núcleos, nos espaços apropriados no decorrer da história anterior. Nesses lugares privilegiados, o consumidor também vem consumir o espaço; o aglomerado dos objetos nas lojas, vitrines, mostras, torna-se razão e pretexto para a reunião das pessoas, elas veem, olham, falam, falam-se. (LEFEBVRE, 2001, p. 130)

Também existe o microfinanciamento, inicialmente voltados a financiar o empreendedorismo dos pobres, depois com linhas para moradias destinadas a apoiar processos de autoconstrução progressiva. Esse tipo de financiamento que serve para aqueles que não possuem compatibilidade com as exigências formais para a concessão de empréstimos financeiros (falta de garantia e capacidade de pagamento), ou seja, habitantes de favelas, passou a ser incorporado também bancos comerciais e a integrar o mercado de capitais. (ROLNIK, 2015, p. 130-136)

Embora as taxas de juros das agências de microfinanciamento sejam tipicamente mais baixas que as dos agiotas informais, elas são mais altas que as cobradas pelas instituições financeiras formais e têm prazos de vencimento muito mais curtos. Assim, se por um lado esse 
sistema amplia a moradia, por outro, aumenta os gastos com habitação, surge uma carência de serviços de saúde, saneamento e educação e, como não contam com segurança da posse, ainda correm o risco de serem despejados de suas casas já reformadas. (ROLNIK, 2015, p. 130-136)

De mais a mais, estimular a demanda por meios da tributação, de truques relacionados a políticas públicas e de outros incentivos (como o aumento do volume de créditos hipotecários de alto risco) não faz surgir necessariamente nenhum aumento da oferta: apenas inflacionados os preços e estimula a especulação. Então é possível ganhar tanto dinheiro, se não mais, em transações financeiras com moradias existentes do que construindo novas (HARVEY, 2014, p. 99)

Já a mercantilização da moradia, bem como o uso crescente da habitação como ativo integrado a um mercado financeiro globalizado, afetou profundamente o exercício do direito à moradia adequada no mundo. A crença de que os mercados poderiam regular a alocação da moradia, combinada com o desenvolvimento de produtos financeiros experimentais e criativos levou ao abandono de políticas públicas em que a habitação é considerada um bem social. (ROLNIK, 2015, p. 32)

Essa mercantilização da moradia se deu, em quase todos os países, por meio da adoção de incentivos (isenções fiscais e subsídios aos juros) para a compra da casa própria. Acontece que, através do financiamento imobiliário para a compra da primeira casa, o mercado global fundamentou-se no endividamento privado, vinculando a vida dos moradores e, todo o processo de globalização, que tem como base a extração de renda e a especulação.

Sem dúvidas, os altos e baixos do mercado imobiliário estão ligados aos fluxos financeiros especulativos, esses excessos e fracassos têm graves consequências para a macroeconomia em geral, bem como todos os tipos de feitos de externalidade sobre o esgotamento de recursos e a degradação ambiental. Além disso, quanto maior a proporção dos mercados imobiliários no PIB, mais significativa a conexão entre financiamento e investimento no ambiente construído tornar-seá uma fonte potencial de macrocrises. (HARVEY, 2014, p. 79)

A crise financeira mundial teve seu ponto máximo em 2008, atingindo mais de 4,5 milhões de famílias o que ocasionou o abandono de bairros inteiros nos Estados Unidos. Essa crise ficou conhecida como crise do subprime, nome que era dado ao crédito bancário oferecido a pessoas de baixa renda, ou seja, um crédito de risco, uma vez que é concedido a pessoas que não oferecem garantias suficientes para beneficiarem-se da taxa de juros menor. Assim, houve o desmoronamento do sistema das hipotecas (estouro da bolha imobiliária), tornando-se centro da crise mundial. 
Essa crise mostrou a ligação íntima existente entre o imobiliário e o financeiro e acabou com a crença que o mercado poderia promover a moradia adequada para todos. Um dos motivos da crise foi a falta de regulação do sistema financeiro, como também a falta de políticas públicas eficazes. Acontece que, mercados não podem garantir uma moradia adequada, uma vez que se faz necessário a presença do Estado de forma ativa.

Outro importante componente na expansão dos sistemas financeiros de habitação, presente também nos sistemas hipotecários, é a disponibilização de recursos públicos sob a forma de subsídios, ou seja, recursos dirigidos diretamente aos compradores de imóveis, assim, mesmo as famílias de menor renda poderão mobilizar suas poupanças para financiar suas moradias no livre mercado, apoiadas por um aporte financeiro oriundo de um fundo público. (ROLNIK, 2015, p. 111)

Assim, percebe-se que essa financeirização que defende menos Estado, mais contratos e transforma o espaço urbano em ativo financeiro, tem como efeito a captura do público pelo privado, fazendo com que as políticas de financeirização sirvam mais para crescer o mercado do financiamento do que aumentar o número de novas moradias adequadas.

\section{A FINANCEIRIZAÇÃO NO BRASIL}

A moradia se tornou um produto, uma mercadoria, pois a produção de casas transformouse em um ativo financeiro, uma forma de lucro para o mercado capitalista. No Brasil, os processos para as construções de moradias são conduzidos pela máquina pública, com recursos públicos, ou seja, o Estado concede às famílias o subsídio para a compra do produto-moradia no mercado imobiliário, criando com isso, massas de periferias. Sobre a posição do cidadão sem moradia e o Estado brasileiro, vejamos o que diz Royer:

Consequentemente, o cidadão beneficiário de direitos passa a ser encarado como um consumidor e a questão habitacional, como uma questão individual de quem pode ou não pode tomar crédito, de quem pode ou não oferecer garantia contra os riscos temidos pelos agentes financeiros. 0 Estado, a quem deveria competir organizar o desenvolvimento social, garantindo o acesso universal à moradia, limita-se a corrigir as decantadas falhas de mercado, sustentando a suposta excelência da racionalidade econômica.

(2009, p. 165)

Assim, a questão habitacional tornou-se uma questão individual e não social, de quem pode ou não tomar crédito ou pode ou não dar garantias, já o Estado, deixa de desenvolver o social, limitando-se a corrigir as falhas do mercado, defendendo a racionalidade econômica. 
Houve, ao longo da história brasileira, segundo Santos, quatro momentos do ponto de vista do papel e da significação das metrópoles:

Quando o Brasil urbano era um arquipélago, pela ausência de comunicações fáceis entre as metrópoles. Num segundo momento, há luta pela formação de um mercado único com uma integração territorial apenas no Sudeste e Sul. Um terceiro momento é quando o mercado único nacional se constitui. E o quarto momento, o atual, conhece um ajustamento à crise de mercado, que é um mercado único, mas segmentado, único e diferenciado, um mercado hierarquizado e articulado pelas firmas hegemônicas, nacionais e estrangeiras, que comandam o território com o apoio do Estado. Não é demais lembrar que mercado e espaço, mercado e territórios são sinônimos. (SANTOS, 1990, p. 78)

O financiamento é necessário à produção e ao consumo da moradia, à produção porque se trata da imobilização de capital significativo durante longo período de tempo, e ao consumo porque habitação é uma mercadoria especial, de alto preço, que exige crédito para sua compra. Essa condição não é recente no capitalismo, por financeirização entendemos a hegemonia do capital financeiro e sua condição de criar capital fictício a partir do mercado imobiliário. (MARICATO, 2014, p. 74)

No Brasil são exemplos de desregulação e privatização de funções e bens públicos em razão da governança a Lei Geral da Copa (Lei 12.663/2012), a Lei Geral das Olimpíadas (Lei 13.284/2016) e Regime Diferenciado de Contratações Públicas (Lei 12.462/2011). O processo de financeirização no Brasil está ligado às reformulações urbanas fundadas em remoção, como por exemplo das obras nos megaeventos esportivos, em que o Estado desapropria terrenos valorizados e ocupados por favelas e entrega ao capital privado.

O setor financeiro apropria-se do espaço como lugar possível de realização do investimento produtivo, ao passo que o setor imobiliário reproduz, aliado à indústria da construção civil, o espaço enquanto mercadoria consumível. Em todos esses momentos de reprodução do capital, a interferência do Estado é fundamental e sua ação desencadeia um processo de revalorização/desvalorização dos lugares e, com isso, expulsão/atração de habitantes, produzindo o fenômeno de explosão do centro-movimento de expulsão de habitantes em direção à periferia, reproduzindo-a. Essas estratégias orientam e asseguram a reprodução das relações no espaço e através dele os interesses privados dos diversos setores econômicos da sociedade que veem no espaço a condição de realização da reprodução econômica. (CARLOS, 2015, p. 17)

Já as metrópoles criadas para comandarem as grandes transformações mundiais trazidas pelo imperialismo exercem uma lógica comandada pelas respectivas lógicas nacionais. Nos países subdesenvolvidos surgem como espaços derivados. O Estado é chamado a adequar o meio 
ambiente construído para possibilitar a ação global das forças mundializadoras no mercado. (SANTOS, 1990, p. 36-38)

Dadas às necessidades de continuidade de produção ampliada da acumulação urbana, e dada algumas barreiras como a raridade do espaço em certas regiões valorizadas e densamente ocupadas das cidades e metrópoles, o setor imobiliário de ponta e o capital financeiro, com o auxílio do Estado, passam atualmente a investir pesadamente na produção habitacional nos espaços periféricos. (VOLOCHKO, 2015, p. 112-113)

Nesse novo momento, a política urbana vem sendo abandonada ou está sendo entregue nas mãos dos interesses imobiliários e financeiros privados, sendo o Programa Minha Casa, Minha Vida, a manifestação acabada desse processo. Há uma naturalização e um fortalecimento da ideia de empreendedorismo e de governança em que o Estado, no plano do poder político, se coloca como representante natural dos interesses econômicos, e não dos interesses da maioria da população. (VOLOCHKO, 2015, p. 112-113)

Em 2012, Raquel Rolnik, então relatora especial da ONU sobre moradia adequada, apresentou um relatório no qual analisou o paradigma predominante das políticas de habitação, com foco no financiamento como o principal meio de fomentar a moradia e concluiu que a plena realização do direito à moradia adequada, sem discriminação, não pode ser promovida somente com mecanismos financeiros, mas pelo contrário, requer políticas públicas e intervenções estatais mais abrangentes e holísticas, baseadas nos direitos humanos.

A financeirização imobiliária no Brasil, apesar da divergência doutrinária, teve dois ápices: um, em 1997, com a criação do Sistema Financeiro Imobiliário (SFI) durante a gestão do então presidente Fernando Henrique Cardoso e, o segundo, no ano de 2000, com a abertura do capital das construtoras na bolsa de valores, o que ocasionou o boom imobiliário, além da interligação de um programa social, o Programa Minha Casa Minha Vida (PMCMV), aos interesses privados.

O Brasil deu dois grandes passos para a moradia, o primeiro foi o modelo de produção massiva da casa própria via mercado, denominado Programa Minha Casa Minha Vida, o segundo os projetos interligados com formas de financiamento e governança, a exemplo as operações urbanas em São Paulo.

Sobre o SFI no Brasil percebe-se que não criou grande produção de moradia, mas ao contrário, foi eficaz para o surgimento de shopping centers, resorts e edifícios comparativos, conclui Royer em sua tese de doutorado:

Após analisar o desenho e o desempenho do SFH e do SFI a elegia do "mais mercado, menos Estado" acaba soando ora como cinismo, ora como 
mistificação. Cinismo por reconhecer que, de fato, é insustentável universalizar o direito à moradia e que alguns permanecerão excluídos, independentemente do êxito da política. Mistificação por ignorar a insuficiência histórica do mercado habitacional brasileiro, inerte sem aportes substantivos de recursos estatais. Neste sentido, apostar na eficiência dos mercados como antídoto à ineficiência da política não só obscurece os sentidos da política habitacional brasileira dos últimos cinquenta anos como reduz a solução de um problema extremamente complexo à simples criação de um ambiente de negócios favorável à acumulação de capital. (Grifo na autora, 2009, p. 162)

Já a criação do Programa Minha Casa Minha Vida ocasionou uma corrida das construtoras para atuar nessa área, o que teve como consequência a escassez de insumos e mão de obra, aumentando o preço dos imóveis no mercado brasileiro. De acordo com o sindicato das empresas de construção o setor cresceu 47,7 no período entre 2003-2013, enquanto que o PIB no mesmo período cresceu 45,9\%, além disso, foram criados 2,23 milhões de postos de trabalhos formais e, a partir de 2010, perto de 1 milhão de unidades financiadas pelo FGTS e SBPE foram lançadas por ano. Assim, não restam dúvidas, que do ponto de vista do crescimento econômico e da geração de emprego o Programa Minha Casa Minha Vida foi um sucesso.

Em decorrência desse crescimento econômico, o Brasil viveu um boom nos preços de imóveis, o que pode ocasionar uma bolha imobiliária. Raquel Rolnik alerta que o índice Fipe-Zap (indicador de preços de imóveis), criado em 2008, apontou uma valorização de 200\% no preço dos imóveis em São Paulo, entre 2008 e 2014. (2015, p.278).

Por outro lado, apesar dos bilhões de reais gastos em subsídios públicos, o Programa Minha Casa Minha Vida não impacta a segregação humana existente, pelo contrário, reforça, produzindo novas manchas urbanas monofuncionais ou aumentando a densidade populacional de zonas guetificadas já existentes. (ROLNIK, 2015, p. 314-316)

Além disso, o programa não contribuiu para qualificar as áreas onde os empreendimentos são implantados e reduzir sua precariedade, pois a forma do condomínio fechado e murado, reproduz enclaves fortificados, fragmentado e desconexo, não transformando ou qualificando. Essa forma de condomínio exige dos moradores o pagamento de uma taxa mensal de manutenção, que em muitos condomínios pesquisados existe a inadimplência. Existem também empreendimentos dominados por grupos ligados ao tráfico de drogas e/ou milícias. Por fim, dados demonstram como a violência está fortemente presente nos empreendimentos. (ROLNIK, 2015, p. 314-316)

Esses novos condomínios habitacionais populares produzidos pelo mercado imobiliáriofinanceirizado nas periferias urbanas mesclam-se, em geral, características urbanísticas de conjuntos habitacionais (bloco de até quatro andares) e de condomínios horizontais fechados 
(sobrados), observando a mesma homogeneização e a mesma excessiva normatização dos usos. (VOLOCHKO, 2015, p. 122-124)

A autoconstrução e o aluguel se soma outras possibilidades de moradia para alguns segmentos das populações menos abastadas das periferias: o endividamento e o financiamento imobiliário. A questão é que esse endividamento é em si mesmo problemático para muitos, sobretudo para os que não têm seus empregos minimamente assegurados. (VOLOCHKO, 2015, p. 122-124)

Em contrapartida, existem características patrimoniais entre o Estado e as empreiteiras no Brasil, pois essas empresas constituem atualmente os atores centrais do processo de construção do complexo imobiliário-financeiro no Brasil, articulando e liderando a nova forma de financiamento da infraestrutura e governança das relações Estado-setor privado: as PPPs. As empreiteiras nacionais surgem quando Vargas implantou seu Plano Nacional de Viação e transforma, em 1945, o DNER em autarquia, passando a ser o primeiro ponto de articulação entre firmas de engenharia nacionais e o governo. (ROLNIK, p. 342-347)

Desde o processo de redemocratização, as grandes empreiteiras converteram-se nos maiores financiadores de campanhas políticas, esfera com maior poder de definir e controlar os contratos de obras. Para as empreiteiras, as doações funcionam como espécie de seguro para garantir que serão contratadas pelo novo governo e pagas dentro dos prazos se tiverem contratos em andamento. (ROLNIK, p. 342-347)

Assim, uma estratégia bem conhecida por empreiteiros consiste em reservar os melhores e mais rentáveis pedaços de terra de suas empreitadas para extrair rendas de monopólios, depois de o resto do projeto ser concluído. Governos astutos com os poderes necessários podem engajar-se nas mesmas práticas. (HARVEY, 2014, p.191)

Por tudo isso, detecta-se que no Brasil o processo de financeirização está ligado às reformulações urbanas fundadas na remoção, com a desapropriação dos imóveis situados nas favelas e sua transferência para o setor imobiliário. Esse setor imobiliário, com o auxílio do Estado, passa a investir na produção habitacional nos espaços periféricos pela necessidade de produção ampliada da acumulação urbana e a raridade de espaços em regiões supervalorizadas.

Pelo exposto, percebe-se, que a política urbana no Brasil está sendo entregue nas mãos dos interesses imobiliários e financeiros privados, como no caso do Programa Minha Casa Minha Vida que reforça a segregação humana e não qualifica as áreas dos empreendimentos, fazendo com que a moradia naqueles lugares não seja adequada. Por isso, defende-se, que para que exista 
a plena realização do direito à moradia não se deve utilizar de mecanismos financeiros, mas sim o Estado ativo, utilizando das políticas públicas de habitação voltadas à concretização do direito social à moradia adequada.

\section{CONCLUSÃO}

O processo de globalização pode ser analisado sob diversos aspectos tanto do ponto de vista econômico, cultural, educacional entre outros e, por causar impacto diretamente na sociedade e nos indivíduos, pode ser considerado um ponto positivo ou negativo, dependendo da corrente doutrinária que o analise.

Em relação aos reflexos que causa nos centros urbanos, mais precisamente no processo de moradia, uma vez que devido a influência da globalização, o indivíduo se desloca da zona rural para a zona urbana em busca de maiores recursos tecnológicos, financeiros e culturais, pode-se dizer que a globalização reflete diretamente nos processos de exclusão e de dominação trazidos pelo capital financeiro e que influenciam as cidades, principalmente, no que se refere ao processo de financeirização de casas destinadas à moradia dos indivíduos.

Com a globalização e a internacionalização das cidades, a qualidade de vida urbana tornouse uma mercadoria. No mundo e, especialmente, no Brasil os governos renunciam seu papel de provedores da habitação para tornarem-se facilitadores criando um setor financeiro habitacional que visa o lucro em detrimento da concretização do direito social à moradia.

Já na financeirização defende-se a menor atuação do Estado nas políticas públicas de moradia e transforma o espaço urbano em um ativo financeiro, capturando o público pelo privado. Ela faz crescer o mercado financeiro, fazendo com que se ganhe mais dinheiro com as transações financeiras do que construindo mais moradias. A financeirização existe também no Brasil, com um processo ligado às reformulações urbanas fundadas na remoção, com a desapropriação dos imóveis da favela.

Assim, pode-se observar que o Brasil investe muito mais em financiamentos através de instituições privadas, com altas taxas de juros, visando unicamente o lucro deste importante setor econômico do país em detrimento do investimento em políticas públicas voltadas à moradia para pessoas de baixa renda.

Percebe-se, também, que o Programa Minha Casa Minha Vida reforça a segregação pois não qualifica as áreas dos empreendimentos. Defende-se, por fim, que a realização do direito à 
moradia não deve ser promovida por setores imobiliários e financeiros privados, mas sim por políticas públicas, promovidas pelo Estado e voltadas à concretização da moradia.

\section{REFERÊNCIAS}

CARLOS, Ana Fani Alessandri. Crise Urbana. In CARLOS, Ana Fani Alessandri (Org). Metageografia: ato de conhecer a partir da geografia. São Paulo: Contexto, 2015, p. 9-23.

CORALO, Giovani da Silva. Planejamento, desenvolvimento e governança: desafios do Poder Municipal, Revista Direito e Desenvolvimento, João Pessoa, v. 6, n. 11, p. 79-93, jan. /jun. 2015

EGLER, Tamara Tania Cohen. Cidade Virtual. XX Encontro anual da ANPOCS GT estudos urbanos. Cidade virtual. Disponível em http://portal.anpocs.org/portal/index, acessado em 10/08/2016

FORJAZ, Spina Maria Cecília. Globalização e crise do Estado Nacional, RAE - Revista de Administração de Empresas. abr./Jun. 2000, São Paulo, v. 40, n. 2, p. 38-50

HARVEY, David. Cidades rebeldes: do direito à cidade à revolução urbana. Tradução Jeferson Camargo. São Paulo: Martins Fontes, 2014.

HOSHINO, Thiago A. P; FRANZONI, Julia Ávila. Direito à cidade $S / A$ : a casa de máquinas da financeirização urbana. Disponível no site http://www.diplomatique.org.br, biblioteca virtual, publicado em 08 de julho de 2016, p. 1-6

LEFEBVRE, Henri. O Direito à Cidade. 5a Ed. Tradução Rubens Eduardo Farias. São Paulo: Centauro, 2001.

MARICATO, Ermínia. Urbanismo na periferia do mundo globalizado: metrópoles brasileiras. São Paulo Perspec. vol.14 no.4 São Paulo Oct./Dec. 2000, p. 1-12

Globalização e Política Urbana na Periferia do Capitalismo. Revista VeraCidade - Ano IV - № 4 - março de 2009, p. 1-25

O impasse da política urbana no Brasil. 3ạ Ed. Petrópolis: Vozes, 2014.

OLIVEIRA, Thiago Vieira Mathias de. A Relação de Poder e a Reorganização da Atuação Estatal No Domínio Econômico Diante dos Processos de Globalização, Londrina, UEL, 2009

ROLNIK, Raq uel. Guerra dos Lugares: a colonização da terra e da moradia na era das finanças. São Paulo: Boitempo, 2015.

ROYER, Luciana de Oliveira. Financeirização da política habitacional: limites e perspectivas. 2009. Tese (Doutorado em arquitetura). USP / Faculdade de Arquitetura e Urbanismo, 2009

SANTOS, Milton. Técnica, Espaço, Tempo: globalização e meio técnico - científico - informal. 5a ed. São Paulo: Editora USP, 1990.

Por uma outra globalização: do pensamento único à consciência universal. 10. ed. Rio de Janeiro: Record, 2003. 
SANTOS, Boaventura de Souza. A globalização e as ciências sociais. São Paulo: Cortez, 2005.

THERBON, Goran. Sociologias, Globalização e desigualdade: questões de conceituação e esclarecimento, Porto Alegre, ano 3, no 6, jul/dez 2001, p. 122-169, O original em Inglês foi traduzido por Roberto Costa e revisado por Eurídice Baumgarten.

VALOCHKO Danilo. Crise Urbana. In CARLOS, Ana Fani Alessandri (Org). Nova reprodução das periferias urbanas e reprodução do cotidiano. São Paulo: Contexto, 2015, p. 105-125.

WOLKMER Antonio Carlos, Pluralismo jurídico, direitos humanos e interculturalidade, Revista Sequência, no 53, p. 113-128, dez. 2006

Trabalho enviado em 23 de agosto de 2016.

Aceito em 21 de outubro de 2016. 